\title{
Birds and mammals in successions of terrestrial ecosystems
}

\section{F. J. Turček}

\begin{abstract}
The succession of terrestrial ecosystems (scres) is studied in aspects of structure, function, production and energetics of the participating organisms. All aspects mentioned involve history and evolution of the communities integrating the ecosystems.

The first approach is the structure, which is particularly dealt with in the present paper. Obviously, most knowledge of ecosystem succession regards the first step only. It indicates the need of study of other aspects, also, and a want for a clear image of structure.

Birds and mammals take part in almost all terrestrial ecosystems. Within the seres of a particular succession - primary and secondary we recognize three, mainly dynamically defined groups of higher vertebrates named, viz. 1) progressive specics cntering populations, 2) regressive, disappearing species and 3) conservative constant species populations, called in the present paper the core of series.

Some problems of structure, the sources from which group 1 penetrates and the function of the particular groups are there dealt with, based on author's own materials and data from some literature.
\end{abstract}

\section{Introduction}

Since Warming, 1895 and later Cowles, 1901 (ex Clements, 1916) defined and described the term succession regarding plant communities, and Clements, 1916 devoted a rather big work to the problem, there are many works and published papers dealing with the dynamic process of succession in general. Though recently Tüxen (1969) stated very little is known about the succession processes, its syndynamics, in spite of much basic work in plant ecology. In fact, most of the works in succession of plant communities, as e.g. Klika, 1941, Ashby, 1961, Kershaw, 1964 and others are of rather general nature, and similar, lacking new views and materials. If we, then, consider that the succession of animal communities is linked with plant community development, we can expect a still poorer result in animal succession investigations. Worst, but understandable, the status of knowledge about the succession of entire ecosystems or fragments of them is more or less approximative, aging of particular seres and series. Meanwhile, new aspects of succession have emerged, such as biological production (Tischler, 1955; Turček, 1957) and energetics (Odum, 1954, a.o.).

Author's Address: F.J. Turček, Institute of Landscape Biology, Department of Landscape Dynamics, Slovak Academy Sci., Banská Stiavnica, CSSR. 
Relatively little has been done and published about the succession of animal communities, or communities of some taxa or life forms. Some literature concerns Invertebrata (Shelford, 1954; Tischler, 1955) while others deal with higher Vertebrata (Lack, 1951; Odum, 1954; Yapp, 1955, 1960; Rabeler, 1955; Tischler, 1955; Clarke, 1957; Turček, 1957; Grodziński, 1959 a.o.), containing species spectra, semiquantitative and quantitative data (Kendeigh, 1961).

In the present paper there are discussed some questions of the succession of both bird and mammal communities, their structure and some general problems of succession based on authors investigations on bird and mammal populations of different communities, with reference to data of literature.

\section{Succession}

Of the three types of ecological succession (e.g. secular, primary and secondary), I shall deal with the primary and the secondary - mostly the latter - as the gaps about secular and to some degree about primary succession would lead to speculations. Definitions of both primary and secondary successions are generally known and accepted and will not be repeated here. An attempt to replace these terms by autotrophic and heterotrophic, respectively, as made by Odum, 1966, is hard to accept, for the two trophic levels, or production communities occur, as a rule, simultaneously and can be separated only on a theoretical basis.

First, some general considerations and statements should be made. Each succession is a dynamic process (Kendeigh, 1961 a.o.). It is forced and advanced by the general vigor of life and its trend to occupy each available space for life. Succession is governed both abiotically and biotically; the predominance of either of the two forces varies in space and time. Most often abiotics predominate about the initial stages. Different initial stages and series - thus, different ways - lead to the same, or similar goal; there are apparently many convergences in the development of ecosystems. The structure, function, production and entropy change with the particular stage, in time and space. What we find in a short-term study is like a snapshot; thus, studies of succession want either stationary investigations, that is to say, on one spot over a long period or a study of the same (similar at least) series, sere at different times and localities. In my view, both approaches are applicable and valid, with some advantages and disadvantages. One of the most relevant properties of succession is the change, in the meaning that the present status becomes peior for the present and melior for the future. In other words, each present status is preparing for the next one, including the climax. Successions are influenced historically and by the current environment. As to organisms, each succession stage is constructed of three elements, e.g. 1) progressive, 2) regressive and 3) conservative components.

Very little is known of the aging of succession, about the age of a sere until mature, or climax (relatively stable) stage. A detailed account of primary succession in both terrestrial 
and aquatic habitats of flood-plains is given by Shelford (1954) and the age of sere estimated for about 600 years. Other accounts regard the well known Krakatau. In secondary succession, especially that of forest ecosystems, the age of different seres to mature or climax stage is given by about 100 years and over, in all cases as extremely variable.

Organisms entering and leaving any stage of succession (sere) originate of, leave for, respectively, different sources of environment. In this sense any sere can be considered polyphyletic (as each climax is a polyclimax, cf. Kershaw, 1964). Obviously, chance plays a not negligible role, especially in early stages (Yapp, 1960). Invasion, occupation and penetration of organisms decrease with progressing stages, filling up the niches. In other words, penetration decreases with increasing homeostasis. If so, then both penetration and homeostasis become one of important factors of succession, on the one hand, and, the question about the sources "of and to" seems answered, on the other. As general phenomenon, communities and ecosystems, by their parts, of higher grade of organization penetrate such of lower level of organization (Turček, 1966). Thus, organisms entering any stage of succession originate from some other sere, its stage, respectively, being higher organized. Other sources are identical or similar stages of identical, or similar, equivalent seres. In this case we can speak of exchange or interchange. The same phenomena apply to ecotones. In fact, successional stages have, to some and different degree, characters of ecotones. Regarding organisms leaving any stage for another, or disappearing, there are two possibilities, such as 1) local extinction, especially in organisms possessing low ability of movement, or 2) emigration, departure. In the latter named case the departing organisms, in fact parts of their populations, spread to and penetrate only equivalent or lower organization level systems. The latter source, though in secondary succession only, of organisms in any stage of succession is their presence in situ, either in dormant, inactive state (as, e.g. roots, nodules, seeds, some microorganisms and vertebrates) or in active state, as for instance, some arthropods, soil animals or even vertebrates. In such presence $a b$ initio in some organisms activation takes place at a proper time (stage). It is, however, clear that this group of $a b$ initio present organisms can strongly influence the trend of succession and its time scale.

\section{Structure}

In the preceding sections we have mentioned three main groups of organisms participating in the buildup of any sere of succession, e.g. progressing or newcomers, regressing or disappearing, and, conservative or steady ones. The first two named are most restricted or limited in time, while the last one passes through the entire sere or at least some stages of it. The more stages involved, the fewer the number of steady species populations. Indeed, an objective reality, in my view, can be considered only the initial and end stages, while the view of all other, say interim, stages can and does involve subjective, 
personal elements and judging. Besides this aspect of gross structure, there are within its groups such elements as producers and consumers and decomposers, different levels of production, all from the standpoint of cycling of materials and flow of energy.

So far we have dealt with questions regarding all organisms: fungi, plants and animals. We turn now to animals, but especially to birds and mammals, as the matter of our own investigations.

Birds and mammals are present in most of successions, beginning with the hydrosere. They are motile enough so that they come in and depart at the particular stages relatively freely. They are bound to place mostly seasonally (breeding territories in birds, burrows, hibernation in mammals), generally independent directly of soils and their connection with plants, except some mono- and oligophags, are mainly alternative and with less respect to species, more to structure, shape, height, mass, foliage profile a.o. Otherwise, these animals react, sometimes strictly, to some abiotic components at any stage, such as light, temperature, relative humidity and other physical features, typical of the stage or sere.

In spite of the rather loose linking of birds and mammals with particular stages and entire seres of succession, these animals are important and interesting in succession, as we will see, for the simple reason that we know them relatively well and have data about them. The "know" regards our experience and knowledge just in succession.

Our interest will be focused to the three groups of animals, mostly birds and mammals, named above, especially to the group called steady, or core of the series. In a previous paper (Turček, 1957) I have stated (p. 593) that "Throughout the entire series of succession the bird population seems to have a kernel of species, while other species come or go and/or change in density with the stages." As to number of species, the changes in time and space show that most species come in within the sere; the two other groups are alternating so that either the departing species group or the core species group is the least one. This varies with the particular seres and with the animal populations considered. In birds, e.g., the core is generally the least, while in mammals the departing group is least (Table 1). Differences are, however, with regards to primary and secondary succession. in the first named the core is the least or nil.

To get a numerical sight, there were analyzed over 50 different ecosystems (Table 1) into 16 different seres, with respect to both bird and mammal populations.

The number of species in the different seres varies from 16 to 89 but always gives the number of species at any end stage. Of that number of species are calculated, derived, respectively, both the absolute and relative numbers of the groups mentioned. As the absolute species numbers vary considerably, the interest and value are the relative ones. Thus, the mean for birds building up the core of succession is 16 percent of all (final) species, with minimum 0 and maximum 30 percent; in mammals the mean percentage of core species is 37 , with a minimum of 29 and maximum 46 per cent, of all species. At the beginning of sere, thus $a b$ initio, there were in birds a mean of 22 percent of end species, 
Table 1. Species number of birds and mammals within some groups in different seres of succession.

\begin{tabular}{|c|c|c|c|c|}
\hline $\begin{array}{l}\text { Total no. species } \\
\text { in end stage/or } \\
\text { end of observation }\end{array}$ & $\begin{array}{r}\text { Present } \\
\text { ab. initio }\end{array}$ & $\begin{array}{c}\text { Core } \\
\text { (steady) }\end{array}$ & Sere & Authority \\
\hline \multicolumn{5}{|l|}{ 1. Birds } \\
\hline 22 & $12 / 50 \%$ & $2 / 9 \%$ & Heats to Scots and Corsican Pine woods & Lack, 1951 \\
\hline 36 & no data & $11 / 30 \%$ & Cut over to Birch-Oak mixed woods & Yapp, 1955 \\
\hline 49 & $5 / 10 \%$ & $2 / 4 \%$ & Moorland to Europ. Spruce and Sitka & Yapp, 1960 \\
\hline 16 & $3 / 19 \%$ & $4 / 25 \%$ & Cut over to Europ. Spruce stand & Rabeler, 1955 \\
\hline 52 & $9 / 20 \%$ & $15 / 29 \%$ & Mat-grass pasture to mixed pine woods & Turček, 1957, '63 \\
\hline 74 & $23 / 31 \%$ & $13 / 18 \%$ & Cut over to mature Oak-Hornbeam stands & Turček, 1951 \\
\hline 63 & $12 / 19 \%$ & $14 / 22 \%$ & Cut over to old Beech/maple/fir stands & Turček, 1953 \\
\hline 63 & $21 / 33 \%$ & $11 / 17 \%$ & Cut over to old Europ. Spruce stands & Turček, 1956 \\
\hline 89 & $30 / 34 \%$ & $21 / 23 \%$ & $\begin{array}{l}\text { Convergent seres of cut over and aquatic } \\
\text { to ash-elm-oak mixed stands }\end{array}$ & Turček, $1957 \mathrm{a}$ \\
\hline 30 & $11 / 37 \%$ & $2 / 7 \%$ & Hydrosere, to swamp forest & Kendeigh, 1961 \\
\hline 22 & $2 / 9 \%$ & $2 / 9 \%$ & Abandoned fields to oak-hickory stands & Kendeigh, 1961 \\
\hline 22 & $2 / 9 \%$ & nil & Hydrosere, to beech-maple stands & Clarke, 1957 \\
\hline 19 & $2 / 10 \%$ & $3 / 16 \%$ & Grassland to hardwood forest & Odum, 1966 \\
\hline 2. $\underset{20}{\text { Mammals }}$ & $9 / 45 \%$ & $7 / 35 \%$ & Landslip to mixed coniferous stands & Grodziński, 1959 \\
\hline 28 & $18 / 64 \%$ & $13 / 46 \%$ & Cut over to old beech-maple-fir stands & Turček, 1953 \\
\hline 24 & $10 / 42 \%$ & $7 / 29 \%$ & Mat-grass pressure to mixed Pine Woods & Turček, 1954 \\
\hline
\end{tabular}

while in mammals there were roughly 50 percent present. Unfortunately, most of the data of literature are incomplete, partial or even undefined, such as "common species", "representative birds", "most important species" a.o., so that they must be accepted with some caution. Interestingly, both the participation of core and of the ab initio species is higher in mammals than in birds. This reflects mainly the more sedentary characters of mammals and the higher motility in birds, respectively, among other factors of impact to structure of series.

Regarding the species involved into the kernel through the succession, with respect both to topical and trophical relations of species populations present, there are some differences in birds and mammals. In primary succession:

a) participating birds in European ecosystems: Falco subbuteo, Phasianus colchicus, Cuculus canorus, Parus caeruleus, Parus palustris in sere from marsh, swamp to ash-elm-oak stands; Anthus trivialis, Buteo buteo, Emberiza citrinella in bare land, landslip to mature woods.

b) participating mammals: Sorex araneus, Microtus arvalis, Arvicola terrestris, Vulpes vulpes, Mustela minuta, Putorius putorius, Capreolus capreolus in sere from marsh, swamp to ash-elm-oak forest; Talpa europaea, Sorex araneus, Sorex minutus, Apodemus flavicollis, Lepus europaeus, Mustela minuta (nivalis) in bare land and landslip to mature woods. No species of birds or mammals were found in sere in sand and gravel beginnings. 
In secondary successions:

c) participating birds: Buteo buteo, Circaetus gallicus, Falco tinnunculus, Tetrastes bonasia, Phasianus colchicus, Cuculus canorus, Caprimulgus europaeus, Troglodytes troglodytes, Phoenicurus ochruros, Anthus trivialis, Carduelis cannabina, Emberiza citrinella, in different seres.

d) participating mammals: Erinaceus europaeus, Talpa europaea, Sorex araneus, Sorex minutus, Lepus europaeus, Apodemus flavicollis, Clethrionomys glareolus, Microtus arvalis, Vulpes vulpes, Mustela nivalis seu minuta, in some seres Capreolus capreolus.

The core of seres considered is thus made by 15 species of birds and 13 species of mammals, in boih types of succession. In primary sere there are 8 species of birds and 11 of mammals, while in secondary the participation is 12 species of birds and 11 of mammals. The total number of species in both types of succession is 28 birds and mammals, of which besides species in common, three species of birds are specific to primary sere, seven to secondary one, while in mammals the same relations are two, and two species, respectively.

Among the so-called core species we find ecologically different elements, from water dwelling ones through steppe, soil animals to forest species. The prevalence of species, though, as can be expected, is euryecous to ubiquist elements. This is one meaning of such species in ecosystems generally. Moreover, some of the core species are able to build up large populations and migrate horizontally. One can, however, wonder about the presence of some "forest species" in the initial stages, such as marsh or bare landscape. Besides the influence of the neighboring ecosystems (cf. the sources!), there play a role in both the trophic and topic relationships of the animals in question. Some examples: Falco subbuteo very often and regularly preys upon dragonflies above marshes, Parus caeruleus and $P$. palustris visit for long periods the reeds in marshes for foods and pry into the stems of reeds for larvae, while the roe-deer is almost common in extensive marshes along the Danube, as is the red fox or the polecat.

- Of interest are the trophical relationships of core animals. In primary sere belong (almost obligatory) 4 species of herbivores, 12 of carnivores including insectivores and 3 to diversivores or mixed eaters; in secondary sere the respective sequence is 7,13 and 3. Thus, the predominance of predators or secondary consuments is obvious.

Briefly, the production and energetics of the succession will be touched. Biological production in animals, thus the secondary one, increases of the initial stage, culminates about the middle stages and slightly decreases toward the end of the sere, (Tischler, 1955, Turček, 1957 a.o.). The same is known of plant succession sere, especially but in succession of forest ecosystems. The culmination of biological production about the middle stages of the particular sere, is, however, hardly surprising, if we assume that there meet the advantages of both the early and the final stages. Here again, we find an analogy with the ecotones: within any sere the deciding factor is time, while within areal distribution of 
ecosystems (or fragments of them) space the same role plays, e.g. where and by which width ecosystems meet and transgrede.

As for bioenergetics, it can be supposed that the best criterion will be the entropy and, perhaps, rate of information flow. Thus, that the entropy will be relatively low in initial stages (negentropy high) and the rate of information increasing, as the number of species and the ecological relationships increase. About the middle stages, when biological production culminates, the entropy will stagnate with a trend to increase. Toward the final stages the entropy will increase and the information rate decrease. So, the ways and amounts of production of materials and of energy flow are rather different, due to the second thermodynamic law.

To sum up, structure, function and functioning (these last named represented by biological production and energy flow) are the dynamic power of any succession of ecosystems.

\section{Discussion}

Information regarding structure and function of seres of succession in ecosystems are of both theoretical and practical interest. Studying the structure, data on specific spectra, adaptability, ability to spread and disperse, competition, biotic potential and relative frequency and importance of particular species or groups of them - all of mostly theoretical interest - will be gained; of more practical interest, however, is information about the relative frequency and importance of groups of species, such as the core ones, data of changes in time, as well on impact of anthropic activities to structure: of this information consequences for conservation and practical (so to say, for manipulation) within the sere can be drawn. Regarding biological production within any sere, is the point or stage of maximal efficiency, while of practical importance is to know the time and place of maximal standing crop, brutto and netto production, available for harvest.

Any ecosystem should be considered an open feed-back system, therefore, in the dynamics, sequence and speed of particular stages as well of the entire sere within major biotic units is, finally, determined by energetics. At present, we know too little about energetic conditions in succession of ecosystems, not to speak of the role and importance of the particular components of it.

With respect to bird and mammalian component populations, of both theoretical and practical importance and interest is their function and, mainly, impact to the particular stages and entire sere. Of some few investigations we know, for example, that jays heavily interfere with sere of secondary succession of pine woods, by planting of oaks and beeches; thrushes and other fruit-eating birds, even the European hare, influence the trend and speed of succession by seed distribution in several cut over areas, pastures and plantations (as many as $\mathbf{5 0 0 0}$ individual woody plants have found the author, per hectare, in pine, spruce and other, mixed plantations, brought in by animals named and still others); we know that 
some populations of thrushes accelerate the "growth up", elevation of soils and so the increase of distance of the surface from the ground water, by distribution of seeds, especially kernels of cherry and elder, mainly but of Cornus sanguinea ir bottom land and flood-plain forests along the Danube (Turček, 1957a). The dense shrub stratum then captures tons of mud brought by flooding, retains debris and itself produces a heavy litter. We know but, also, of changes in successional trend caused by large herbivores, deer in particular, by browsing: they eliminate some plants and woods, enabling thus a replacement by more agressive (and less palatable) woody plants (spruce, for example). Altogether but, we know of these, in my view, very important, paramount processes in succession, a little only. Lastly, some words about the so-called core of succession. First, this is a reality, both in plants and animals, thus in ecosystems. As to function of core animals, it has been shown that they are mostly predators, thus secondary consuments and tertiary producers. They feed upon herbivores, lowering so the pressure of last-named ones exerted to producers: to the advantage of succession as such. While some of the predators are occasional or permanent visitors for feeding in any stage, the herbivore group out of core species is mostly resident and makes 21 and 30 percent of all core species in primary and secondary succession, respectively.

Of all points-of-view involved, the core of entire ecosystems and their seres of succession deserve most of the attention. Instead of, or parallel to, mere description of succession seres - prior of syntheses not thoroughly founded - more and intensive analytical work is needed, utilizing all the instrumentation, equipment and technical progress at disposal.

\section{References}

Ashby, M. 1961. Introduction to plant ecology. McMillan Co., Ltd., London pp. 249.

Clarke, G.L. 1957. Elements of ecology. J. Wiley Sons, Inc., New York pp. 534.

Clements, F.E. 1916. Plant succession. Carnegie Inst., Washington, 242: 1-512.

Grodzinski, W. 1959. The succession of small mammal communities on an overgrown clearing and landslip mountain in the Beskid Sredni, W. Carpatians. Ekologia Polska A. 7(4): 83-143.

Kendeigh, S.C. 1961. Animal ecology. Prentice Hall, Inc., Englewood Cliffs, N.J. pp. 468.

Kershaw, K.A. 1966. Quantitative and dynamic ecology. E. Arnold, Ltd., London. pp. 183.

Klika, J. 1941. Praktikum rostlinné sociologie. Melantrich, Praha, pp. 385.

Lack, D. and E. Lack. 1951. Further changes in bird-life caused by afforestation. Journ. Anim. Ecol. 20(2): 173-179.

Odum, E.P. 1954. Fundamentals of ecology. Saunders Co., Philadelphia, pp. 384.

Odum, E.P. 1966. Ecology. Holt-Rinehart-Winston, N.Y., pp. 152.

Rabeler, W. 1955. Die Artenfolge in den Vogelbeständen der Oberharzer Fichtenforsten. Mitt. Flor.-soz. Arbeitsgem. N.F. 5, Stolzenau/Weser: 193-197.

Shelford, V.E. 1954. Some lower Mississippi Valley flood plain biotic communities; their age and elevation. Ecology 35(2): 126-142.

Tischler, W. 1955. Synökologie der Landtiere. Fischer, Stuttgart, pp. 414. 
Tüxen, R. 1969. Stand und Ziele geobotanischer Forschung in Europe. Ber. Geobot. ETH, Stiftung Rübel, Zürich 39: 13-26.

Turcek, F.J. 1951. On the stratification of the avian population of the Querceto-Carpinetum forest communities in Southern Slovakia. Sylvia 13(3): 71-86.

Turček, F.J. 1953. Ecological analysis of population of birds and mammals of the primeval forest on Polana Mts., Slovakia. Rozpr. II. tr. Ceské akademie 62(3): 1-51.

Turček, F.J. 1954. Die Vögel und Säugetiere der Nardeten-Weiden in der Umgebung von Banská Stiavnica. Biologia 9(3): 267-277.

Turcek, F.J. 1956. On the bird population of the spruce forest community in Slovakia. Ibis 98(1): 24-33.

Turček, F.J. 1957. The bird succession in the conifer plantations on matgrass land in Slovakia (CSR). Ibis 99: 587-593.

Turcek, F.J. 1957a. On the bird population of the bottomland forests around the Danube, with special reference to its economic importance. Aquila 63-64: 15-40.

Turcek, F.J. 1963. Vögel der Kiefernwälder in den Tatra-Vorgebirgen. Biologia 18(7): 504-514.

Turcek, F.J. 1966. The zoological significance of ecological and zoogeographical borderlands. Acta Zool. Acad. Sci. Hung. Budapest, 12: 193-201.

Warming, E. 1895. Plantesamfund. Revised translat., 1909: Oecology of plants. Clarendon Press, Oxford pp. 422 .

Yapp, W.B. 1955. The succession of birds in developing Quercetum petreae. The North Western Naturalist 3: 58-67.

Yapp, W.B. 1960. The colonization of coniferous plantations by birds. Proceedings XIIth Internat. Ornithol. Congr. Helsinki: 801-803. 